\title{
La ficción biográfica entre Francia, Argentina e Italia (Schwob, Borges, Wilcock, Tabucchi)
}

\author{
Ariane Eissen ${ }^{\bullet}$ \\ Université de Poitiers \\ Traducción: Silvia Zenarruza de Clement
}

\section{Resumen}

La ruptura introducida por la Vidas Imaginarias de Marcel Schwob en el género de la biografía ha seducido a Jorge Luis Borges, cuya influencia se ha ejercido a su vez en escritores como Juan Rodolfo Wilcock o Antonio Tabucchi. Estudiando la práctica de la ficción biográfica en esos cuatro autores, este artículo pone el acento sobre sus poéticas y el tipo de relación instaurada con el lector.

\section{Palabras clave}

- escritura de vida · ficción · vidas de hombres infames

\begin{abstract}
The new departure introduced by Marcel Schwob's Vies Imaginaires in the genre of biography did not fail to attract Jorge Luis Borges whose influence in its turn was paramount with writers such as Juan Rodolfo Wilcock and Antonio Tabucchi. This article examines how these four writers produce their biofictions emphasising their poetics and the relationship they develop with their readers.
\end{abstract}

\section{Key words}

· Life-writing · Fictionality · Lives of Infamous Men 
Midiendo con delicia el poder que tienen los libros de viajar en el tiempo y de dinamizar los espíritus creadores a distancia, Florence Delay declara a propósito de la huella de Marcel Schwob: "Cuando se desdramatiza la literatura, ya sea que se hable de vientos, corrientes, afinidades electivas, las fronteras quedan abolidas y se descubre la familia en la que somos esperados personalmente. Al final de cuentas, nosotros que nunca somos lo suficientemente libres, lo somos de elegir quién influenciará enormemente nuestras vidas, nuestra obra» (Delay, 2006: 14).

Es así como ella indica que las Vidas imaginarias (1896) han podido contribuir para dar un impulso a Alfonso Reyes para sus Retratos reales e imaginarios (1920), más subterráneamente a Roberto Bolaño en la Literatura nazi en América (1996) y por supuesto a Jorge Luis Borges, en la Historia universal de la infamia (1935). Sobre todo para "el género maravilloso de las "biografías sintéticas" que ha practicado en la revista El Hogan» (Idem).

La circulación del micro-género de la ficción biográfica entre Francia y América Latina, e inversamente, ya ha sido estudiado y se podría intentar cartografiar estas idas y venidas, incluyendo además otros países europeos, como la Inglaterra de Max Beerbohm (Seven Men, 1919) o la Italia de Alberto Savinio (Narrate, uomini, la vostra storia, 1942). Me limitaré aquí a cuatro autores, frecuentemente asociados por la crítica reciente: examinaré los proyectos de Marcel Schwob y de Jorge Luis Borges en las dos obras ya citadas y también haré un excursus en tierra italiana con La Sinagoga degli iconoclasti de J. Rodolfo Wilcock (1972) y Sogni di sogni de Antonio Tabucchi (1992).

El acercamiento entre Schwob, Borges y Tabucchi ya ha sido establecido por Pilar Hualde Pascual (1996) y Francisco García Jurado (2004), mientras que Víctor Gustavo Zonana (2000) ha mostrado la inflexión pesimista dada a la biografía por Schwob, Borges y Wilcock a través de su interés marcado por las vidas de criminales.

A pesar de su encuentro en torno a los mismos autores, o casi, las perspectivas críticas de estos tres artículos son bastante diferentes. Privilegiando las biografías imaginarias de personajes de la Antigüedad greco-romana, Pilar Hualde Pascual y Francisco García Jurado utilizan sus competencias de expertos en la Antigüedad para analizar los mecanismos de reescritura y mostrar hasta qué punto el recuerdo de los textos griegos o latinos se alía a referencias mucho más recientes, en una abolición de la diferencia de los tiempos históricos, donde se lee la marca de Jorge Luis Borges. Víctor Gustavo Zonana amplía la cuestión buscando caracterizar la práctica de la biografía imaginaria, históricamente, poéticamente y en sus efectos posibles sobre el lector en un punto de vista crítico que haré mío, deseando prolongar su reflexión.

A manera de preámbulo, demos lugar a la historia literaria y examinemos la ruptura que introduce el prefacio de las Vidas imaginarias en el género de la biografía. Lúcido texto sobre la fractura que se ha instalado progresivamente, a partir del siglo XVIII, entre las ciencias sociales y las letras, fractura que, a sus ojos debe permitir en adelante a los escritores reivindicar la autonomía de su discurso y el derecho a la imaginación, Marcel Schwob proclama solemnemente la disociación de la biografía y de la historia: «La ciencia histórica nos deja en la incertidumbre sobre los individuos. No nos revela sino los puntos por donde fueron unidos a las acciones generales [...] El arte está opuesto a las ideas generales, sólo describe lo individual, no desea sino lo único» (Schwob, 2004: 53). 
Un territorio propio es atribuido entonces a la literatura: el interés por las exigencias singulares, por las rarezas de los recorridos individuales y las especificidades de seres profundamente únicos y misteriosos. En oposición a los propósitos científicos del naturalismo a la Zola o de la novela psicológica a la Paul Bourget, que escrutan la interacción de las leyes y de los determinismos diversos (genéticos, sociales, psicológicos) en el desarrollo de una vida, Marcel Schwob desea hacer de la escritura biográfica el lugar de un renunciamiento al espíritu de sistema, so pena de transformar la persona en estudio, en inteligible y analizable.

Esta desconfianza frente a ideas organizadoras, aclaraciones generalizadoras, se acompaña también de una suspensión de todo juicio moral, de toda valorización de trayectorias ejemplares, en beneficio de una aceptación democrática de cada criatura:

tal vez no habría que describir minuciosamente al hombre más grande de su tiempo, o contar

la característica de los más célebres en el pasado, sino contar con el mismo cuidado las existencias únicas de hombres, ya sea que hayan sido divinos, mediocres o criminales (Ibíd. 60).

Y a eso es a lo que se dedicó Marcel Schwob antes de la escritura del libro, cuando presenta así un ciclo de relatos para ser publicados en Le Journal en 1894: "Comenzamos hoy la serie: Vida de algunos poetas, dioses, asesinos y piratas así como de varias princesas y mujeres galantes destacadas y dispuestas según un orden placentero" (Schwob, 2004: 416).

Las mujeres son menos numerosas que lo que este anuncio dejaría creer, ya que Vidas imaginarias no incluye sino a "Clodia, matrona impúdica» y a «Katherine la Encajera, hija amorosa» entre las «damas galantes» y a «Pocahontas» como única "princesa», grupo en el que hay que agregar a «Septima, hechicera», quien no entra en ninguna de estas categorías.

El programa se sigue en lo que concierne a los poetas, a condición de ampliar la noción a los artistas en general, lo que permite poner lado a lado a Lucrecio, Petronio, Cecco Angiolieri, Paolo Uccello o Cyril Tourneur, hasta a los señores Burke y Hare, que practican el asesinato como una de las bellas artes ${ }^{1}$. El libro trata igualmente de varios piratas (William Phips, capitán Kid, Walter Kennedy o El Mayor Stede Bonnet), mientras que se puede citar a Empédocles como «dios supuesto» y notar la aspiración a lo divino de personajes tales como "Eróstrato, incendiario», «Frate Dolcino, hereje», o aún a «Nicolas Loyseleur, juez» $\mathrm{y}$ «devoto de la Virgen».

El encuentro de personajes dispares, apenas ordenados por la disposición cronológica del libro, parece dar testimonio de la oscuridad de un mundo heterogéneo, atravesado por la violencia y la locura y casi incomprensible. Frente a ese «caos de rasgos humanos", el escritor no cuenta más que con su estilo: "En medio de esta grosera reunión el biógrafo separa y clasifica algo que le sirva para componer una forma que no se parezca a ninguna otra» (Schwob, 2014: 60). Constatación que plantea la doble cuestión de las fuentes a partir de las cuales él trabaja y de los códigos literarios en los que confía para elaborar su relato. La fuentes provienen de la cultura libresca, puesto que dan testimonio de la formación clásica de Marcel Schwob, de su anglomanía y de su gusto por el Medioevo; se funda tanto en los doxógrafos de la Antigüedad para Crates, como en los relatos de Defoe para evocar a los piratas o en menciones de archivos para exhumar los nombres de Alain el Gentil o de Katherine la Encajera e imaginarles una vida. Los códigos literarios son variados: provienen del cuento, de la hagiografía, del texto irónico (Cyril 
Tourneur) o no (Empédocles), del compendio de anécdotas (sobre Crates, por ejemplo), y recurren frecuentemente a los esquemas trágicos, de lo que da cuenta la frecuencia del tema de la hibris (para Uccelo, por ejemplo).

El autor se convierte en una "divinidad inferior» (Ibíd.: 59) o se podría decir «secundaria». O sea que no crea ex nibilo sino que forja a partir de un material dado previamente. Los relatos que propone son de buen grado «relatos de relatos» que reciclan otros y lo hacen aparecer como traductor, imitador y hasta falsificador. Divinidad incapaz de engendrar por ella misma, el autor no fija tampoco un sentido último, que diría la verdad, moral o científica, la constante de una idea fija o las bases de un sueño despierto. Revela las tendencias profundas a la anarquía y a la destrucción en nuestras existencias. Deshace la historiografía oficial privilegiando los personajes marginales ${ }^{2}$ tendiéndonos la imagen de «ínfimos» ${ }^{3}$ o aún «infames».

La erudición afilada de Marcel Schwob, la extensión de sus lecturas, sus competencias políglotas son rasgos que comparte con Jorge Luis Borges, Juan Rodolfo Wilcock y Antonio Tabucchi. Se sabe, Jorge Luis Borges lo reconoció tardíamente dos veces, la influencia de Marcel Schwob en la concepción de Historia universal de la infamia ${ }^{4}$. ¿Qué caminos lo han conducido hacia la obra del francés? Florence Delay propone la hipótesis del rol de Rafael Cansinos-Assens, él mismo traductor de las Confesiones de un inglés comedor de opio y gran conocedor de los escritores de fin de siglo, encontrado en Madrid cuando Borges tenía veinte años, pero Jean-Pierre Bernés (1993: 1484) sitúa el descubrimiento de Borges de la obra de Schwob en una biblioteca de Ginebra, en 1918. A esto hay que agregar una admiración común por De Quincey y Stevenson 5 . Stevenson, que Wilcock tradujo para la revista Sur, es también un posible eslabón uniendo éste a Schwob, así como los Brief Lives de John Aubrey, citados en el prefacio de Vidas imaginarias y que Wilcock hizo conocer en italiano publicado por Adelphi en 1977, aun cuando esta publicación es posterior por algunos años a La sinagoga degli iconoclasti (1972).

Por una curiosa casualidad aparecen también en 1972 las Vite immaginarie en una traducción de Fleur Jaeggy ${ }^{6}$. Dando cuenta conjuntamente de La sinagoga degli iconoclasti y de esta edición italiana del libro de Schwob, Pier Paolo Pasolini lo presentará como un "clásico7», lo que hace aún más probable el hecho de que Juan Rodolfo Wilcock lo haya leído antes de publicar La Sinagoga. En cuanto a Tabucchi, no sólo una serie de indicios ${ }^{8}$ en Sogni di sogni nos reconducen a Schwob sino que declara directamente en El Pais:

Es un poco como el juego de las tres cartas. A mí Marcel Schwob me ha gustado siempre muchísimo. Borges, es superfluo decirlo. A veces las coincidencias no son conscientes, porque, como decía el proprio Borges, «la literatura no es un tren que corre por la superficie, sino un río que corre en profundidad y de vez en cuando asoma»?

Lo más importante no es tal vez establecer la existencia de un río subterráneo corriendo de Schwob a Tabucchi y pasando por Borges y Wilcock. Conviene más bien notar que circulamos de unos a otros en los dos sentidos y que nuestra lectura de Schwob, por ejemplo, es necesariamente borgiana, como lo confiesa Florence Delay, simplemente: «Ésta [la pasión por Marcel Schwob] vendría más tarde y, curiosamente, cuando yo comprendería cuánto el autor de "Los señores Burke y Hare, asesinos" había contado para Borges» (2006: 13). De la misma manera, el autor del texto de la contratapa de Vite immaginarie en Adelphi hace observar: 
«[...] oggi, se tanti lettori scoprono in Borges gli incanti più sottili e vertiginosi del fantastico e di una certa occulta matematica della narrazione, riconosceranno in Schwob un maestro e un modello di quella letteratura».

Clara invitación a inclinarnos hacia el examen cruzado de la poética de Schwob y de Borges (y de otras obras del corpus), sin sucumbir a los rigores de la cronología.

Robert Ziegler, uno de los especialistas de las Vidas imaginarias, observa que «en sus últimas vidas, Schwob ensancha la interconexión entre rechazo de las leyes, autocreación, autoridad narrativa y ostracismo social» (2009: 29).Y sugiere que el autor puede así reflejar los perfiles de su gesto creador en sus personajes en tanto que en su prefacio ha proclamado orgullosamente la autonomía de su proyecto artístico, su ruptura con las reglas científicas y los usos sociales de la biografía, tradicionalmente dedicada a la celebración de los grandes hombres o a dar de los maleantes un valor ejemplar en su crimen. La misma «interconexión» se verifica en nuestros otros tres autores quienes, cada uno a su manera, hacen valer la originalidad de su proyecto, que equivale siempre a una forma de rechazo.

Por otra parte, los «umbrales ${ }^{10} »$ de los libros precisan las intenciones de los escritores y nos comprometen a captar finamente las particularidades de su empresa poética. Solo Juan Rodolfo Wilcock no escribe ni prefacio ni colofón en La Sinagoga degli iconoclasti, aun cuando se puede considerar que el último texto desliza algunos indicios sobre lo que se espera del lector ${ }^{11}$. Jorge Luis Borges precisa en dos prefacios sucesivos lo que ha representado para él la Historia universal de la infamia: «los ejercicios de prosa narrativa» son a la vez un homenaje a sus modelos, literarios (Stevenson, Chesterton, Carriego) o cinematográficos (Von Sternberg), una tentativa parcialmente fallada, que abusa de «algunos procedimientos» (1955), y una prueba de la dignidad de la lectura, «actividad posterior a la de escribir: más resignada, más civil, más intelectual» (Borges, 1974: 289). En 1954, el juicio ambivalente se precisa y se colorea de una cierta melancolía. Un término, el de «barroco» se le adosa al estilo adoptado, que correspondería al «irresponsable juego de un tímido que no se animó a escribir cuentos y que se distrajo en falsear y tergiversar (sin justificación estética alguna vez) ajenas historias». Sin embargo ese juego es fuente de placer, un placer que el autor espera sea compartido por su lectorado y que compensa un desencanto inicial, hecho de sentimiento de vanidad («Los doctores del Gran Vehículo enseñan que lo esencial del universo es la vacuidad») y de una desdicha personal a la que no está asignada ninguna causa («El hombre que lo ejecutó era asaz desdichado» (Ibíd.: 291). La difracción de la imagen del autor en el umbral del libro parece más intimista en Antonio Tabucchi, entre la dedicatoria a su hija Teresa («che mi ha regalato il quaderno dove è nato questo libro» (2001: 9), epígrafe sacado de una antigua canción china (¿ficticia?) ${ }^{12}$ y nota firmada con sus iniciales. En esas pocas últimas líneas se afirma aún más netamente que en Borges el rol consolador de la literatura: la imposibilidad de conocer la vida onírica de los artistas apreciados ${ }^{13}$, el alejamiento ligado a la muerte dejan lugar a la «tentazione di rimediare», «chiamando la letteratura a supplire a ciòche è andato perduto» (2001: 13).

Escribir a partir del duelo, de la pérdida, de la privación: tal es uno de los hilos posibles que se tejen entre Borges y Tabucchi. Pero su designio de biógrafo ¿es exactamente el mismo? Los relatos de Borges, a pesar de su barroquismo que de pronto ralentiza el ritmo narrativo por acumulación de detalles digresivos, de pronto lo acelera hasta la elipsis, siguen el orden cronológico y están como imantados por el desenlace del cuento, que coincide con la muerte del personaje. Salvo en lo 
que concierne a la Viuda Ching, los momentos últimos están descritos de manera espectacular (particularmente para Bill Harrigan y Hákim de Merv) y manifiestan frecuentemente la lógica de una existencia, como para Monk Eastman, que muere como ha vivido, privilegio explícitamente rechazado a Lazarus Morell. Las últimas horas de una vida ¿serían el lugar de la evaluación verdadera, la que confiere o niega valor a la persona? Esta idea heredada del ideal épico de la Antigüedad, el tema de la «bella muerte», reaparece sin duda en Historia universal de la infamia, si se piensa en el cierre de "El incivil maestro de ceremonias Kotsuké no Suké», que se termina no con el degüello de Kotsuké (rehusa hacerse el hara-kiri) sino con el suicidio de sus perseguidores, habiendo obtenido su fin tardíamente. En efecto, Borges concluye a propósito de estos últimos: «Éste es el final de la historia de los cuarenta y siete hombres leales — salvo que no tiene final, porque los otros hombres, que no somos leales tal vez, pero que nunca perderemos del todo la esperanza de serlo, seguiremos honrándolos con palabras» (1974: 323). El elogio se combina entonces con una autocrítica de alcance colectivo y subraya el motivo de la decadencia: el heroísmo no se marcaría de ahora en más en las conductas sino en una celebración puramente formal de los hombres de coraje, lo que reenvía al desencanto que hay en vivir un período de decadencia ${ }^{14}$. En contraste, el protocolo literario inventado por el «nostalgico di sogni ignoti» que es Antonio Tabucchi es más lúdico y liviano: reabriendo, en cada evocación de sueño, la posibilidad de encontrar un artista en el abandono a su onirismo, el relato de sueño continua dejando vivir al biografiado, ya sea que se despierte o no al final del cuento. Para Tabucchi, y es una notable excepción en el interior de nuestro corpus de vidas imaginarias, el punto de vista no es el de la muerte, sino de una suerte de vida aumentada, dotada de una protuberancia imaginaria, un sueño inventado pero no imposible stricto sensu ${ }^{15}$.

Ciertamente habría que sostener esas dos pistas interpretativas, apenas esbozadas aquí, pero que al menos revelan que a través de los conjuntos de relatos se dibuja también en filigrana un retrato de los autores, que no se limita a los umbrales de las obras sino que se difracta en la serie de biografías y en la elección de los personajes. Tabucchi, por ejemplo, es un nuevo Dédalo, creador de un laberinto (textual) de donde puede volar hacia la luna un Minotauro/Ícaro, nos dice el primer sueño de Sogni di sogni. Encerrado en un universo de palabras que él ha creado sin embargo, deja la puerta abierta al vuelo imaginativo del lector. Marcel Schwob y Jorge Luis Borges parecen proyectarse en la imagen del autor asesino, aquél cuya obra supone matar: en «Hombre de la esquina rosada», el narrador se revela bien in fine el asesino, así como lo ha hecho notar Borges en la noticia autobiográfica citada más arriba; y después de haber gozado de matar a sus presas, una vez que le habían contado su vida, el señor Burke «se interesó sólo por el aspecto real, siempre variado para él, de la muerte» (Schwob, 2004: 155) y a contentarse de esta última etapa, sin escuchar más a sus víctimas. Esta alianza macabra de la literatura y de la crueldad se revierte, sin embargo, en ocasiones en Schwob por un sentimiento de piedad y empatía para sus personajes, femeninos sobre todo (Katherine la Encajera por ejemplo). En cuanto a Borges se refleja sin duda en las figuras de impostores que aparecen en la colección de relatos, los que convencen por una palabra mentirosa, los que seducen por fábulas o invenciones (de Lázarus Morell a Hákim de Merv pasando por Tom Castro). La imagen sostenida por Juan Rodolfo Wilcock en La sinagoga degli iconoclasti es más fugaz y difícil de 
aprehender. A lo sumo se puede notar que él está indirectamente en el libro, vía la evocación de su antepasado Carlo Olgiati, monomaníaco inventor de sistema, cuyas elucubraciones regresivas se enlazan con el tema borgiano de la decadencia y confirman que la ficción biográfica no es más el lugar de una celebración memorial y de un homenaje dedicado al pasado. La iconoclastia que Wilcock muestra en el título de su volumen es entonces también la suya.

En esas condiciones, si el lector no está ya más invitado a admirar (o condenar) ni a descubrir leyes morales o científicas, ¿̨cuál puede ser el lugar que le está asignado?

Es necesario tal vez introducir aquí una diferencia importante en el interior del corpus. Mientras que Marcel Schwob declara abruptamente que «[el biógrafo] no tiene que preocuparse por decir verdades» (Schwob, 2004: 59) y que Antonio Tabucchi propone en la segunda sección de su libro ("Coloro che sognano in questo libro») notas formalmente calcadas del modelo del diccionario pero que continúan asumiendo la subjetividad mostrada en el umbral del volumen, Jorge Luis Borges y Juan Rodolfo Wilcock hacen muestra de cientificidad exhibiendo una bibliografía. Parecen así poder recuperar una inquietud de exactitud histórica. Sin embargo, de nuevo hay que hacer una distinción probablemente entre ellos.

En Jorge Luis Borges: ceuvre et manœuvres, Annick Louis ha mostrado cuánto la Historia universal de la infamia corresponde "a una tentativa de producir una obra marcada por un cuestionamiento de las convenciones genéricas» (1997: 185). Jugando con las diferencias entre un soporte (la RMS, donde aparecen los textos aislados, con una orientación literaria) y por otro (la colección «Megáfono» en Tor, para el conjunto de relatos, especializada en la historia novelada), concibiendo textos que se alimentan de discursos convenidos (la confesión del maleante en la prensa, el «develamiento de un mundo oculto» (Ibíd.: 143) por el de periodista o el análisis socio-psicológico del experto) pero para desviarlos, pasando, en el interior mismo de Crítica, de un género de ilustraciones (pretendidamente documentales) a otro (anacrónicas y novelescas), Borges se presenta como una «especie de simulador de historiador» (Ibíd.: 146) que, como tal, no puede engañar a su lector sino puntualmente, dejándolo creer en la seriedad de una fuente totalmente inventada ${ }^{16}$. El proyecto de la Sinagoga es más radicalmente provocador y desconcertante. En efecto, Juan Rodolfo Wilcock se refiere al final del libro al panfleto de Martin Gardner, In the Name of Science ${ }^{17}$, recuperando un cierto número de sus personajes (Littlefield, Carroll, Kinnaman, Piazzi-Smith, Lust), pero no dice una palabra de los otros. El lector está entonces invitado a pronunciarse sobre su probable inverosimilitud. Y la función referencial del relato se encuentra así reactivada. Se observa perfectamente que este fenómeno perturba a Pier Paolo Pasolini ya que declara haber leído el libro como una «enciclopedia divulgativa» (1979: 30).Y utiliza como prueba las tesis de Charles Carroll de Saint Louis (Missouri), autor de The Negro a beast (1900) del cual he aquí un vistazo: "Come gli altri mammiferi, il negro manifesta una specie di mente, qualcosa tra il cane e la scimmia, ma è completamente privo di anima» (Wilcock, 1972: 95).

Ahora bien, la conclusión de Pasolini es falsa pues lo real supera aquí lo imaginario y ¡la existencia de ese autor racista está perfectamente probada! De manera que la doble reacción de Pasolini, que declara haber leído La Sinagoga «riendo como un loco» antes de haber sido atacado por un «sentimiento de náusea» y de una "voluntad de olvido ${ }^{18}$ ", es rasgo de un malestar que no se puede barrer fácilmente y que no se explica por la sola frecuentación de psicópatas presentados por Wilcock. 
Si el lector los juzga ficticios por el hecho de que tales locos no podrían existir, hay que darle garantías sobre las cuales fundar su confianza y es particularmente difícil después del delirio nazi, sugiere el autor. Y si los admite como reales, tiene que admitir que la locura y la razón están en una relación de vecindad muy estrecha, lo mismo que la marginalidad y el orden establecido. Pues algunas de estas elucubraciones tuvieron una audiencia: las teorías de Charles Piazzi-Smith gustaron al presidente de los Estados Unidos de la época y las de Hans Hörbiger, autor de la Doctrina de la Cosmogonía Glacial, sedujeron a Hitler ${ }^{19}$. Wilcock sugiere que lo irracional de los entusiasmos científicos se manifiesta en todas las épocas: "Come nel Settecento la gente alla moda si offriva per bizzarria alle scosse elettriche, la gente alla moda del primo Novecento volle offrirsi per igiene alla radioattività" (Wilcock, 1972: 57).

Dicho de otra manera, cada cual puede, a pesar suyo, ceder al prestigio de teorías ilusorias. Así los personajes de Wilcock son iconoclastas, no tanto porque sus divagaciones rompen con las teorías recibidas sino porque, en el uso que Wilcock hace de ellos, sirven de revelador a las locuras admitidas.

Si Juan R. Wilcock tiene una manera específica de sumergir al lector en la perplejidad, los otros tres autores de nuestro corpus no lo tratan con indulgencia tampoco. La ficción biográfica no se produce sin trabajo de estilo, hibridación genérica o autoridad autoral reducida al simulacro, como se ha visto. Y los autores parecen entonces jugar a veces con una complicidad de estetas o de hombres de cultura con el lectorado, o dejar de lado toda intención demostrativa o explícita. Por razones de espacio, no tomaré más que tres tipos de ejemplos de efectos enigmáticos en las colecciones de relatos.

El prefacio de Vidas imaginarias valora el detalle caracterizador ya que el biógrafo debe aprehender «un hombre en todas sus anomalías» y señalar «su rasgo único, que lo diferencia para siempre entre los hombres» (Schwob, 2004: 54-55). Pero en realidad, las notaciones descriptivas en Schwob crean un sentimiento de extrañeza e instalan una presencia misteriosa, sin que las palabras permitan figurarse los perfiles del personaje a pesar del modelo pretendidamente pictórico que se ha dado el autor (Holbein, Hokusai). Así las sonrisas del esclavo del que Lucrecio está enamorado «tenían una fuente profunda y tenebrosa como los ríos de Africa ${ }^{20}{ }_{\text {»: la comparación }}$ sólo tiene valor evocador en la ensońación de un lector, un poco como si el universo simbolista de Schwob viniese a contrariar aquí los objetivos que él le asigna al biógrafo.

Uno de los subterfugios autorales de Borges en Historia universal de la infamia toma la forma de una ironía a veces indecidible. Al lado de definiciones voltairianas (la guerra como «otro desorden» (Borges, 1974:315) en El proveedor de iniquidades Monk Eastman), de antífrasis evidentes (la "ardiente serenidad» (Ibíd.: 323) con la que los vengadores del señor de la Tour de Ako se hacen harakiri), otros pasajes se abren a la interpretación de manera más incierta: por ejemplo, ¿̨hay que suspender todo juicio ético y político ante el morceau de bravoure que abre «El espantoso redentor Lazarus Morell» y sitúa al esclavismo de los Negros en el centro del proceso cultural de América? Y ¿qué pensar del tono neutro adoptado por Borges cuando relata las relaciones de Monk Eastman con los medios demócratas? La neutralidad aparente del autor ¿es garantía de indiferencia, de desaprobación implícita o libertad de juicio acordada al lector? Inversamente los juicios mostrados, en apertura o cierre de «El incivil maestro de ceremonias Kotsuke no Suké», por ejemplo, ¿̨deben tomarse al pie de la letra? La elección de Borges de condena o de revelación en la evocación 
de los infames manteniendo distante toda postura de explicación, perfectamente analizada por Annick Louis, no carece de zonas de sombra para el lector.

Inversamente, las orientaciones políticas de Tabucchi son perfectamente claras en «Coloro che sognano in questo libro». Juzga así «infelice» (Tabucchi, 2001: 81) un poema de Majakovskij en honor de Lenín. Pero, precisamente, la subdivisión del libro en dos partes, los relatos de sueños y las notas biográficas, plantea la difícil cuestión del valor biográfico del relato de sueño. He tratado de mostrar en otro lugar (Eissen, 2007: 223-233) que, en la constitución del proyecto tabucchiano, el relato de sueño no puede no tener un alcance biográfico, pero que no es fácil de captar. Me conformaré aquí entonces con algunas indicaciones para hacer comprender ese doble aspecto. En ciertos casos, la articulación del relato de sueño y del relato biográfico es límpida. Así en su universo onírico, el Pessoa de Tabucchi recibe la revelación que dictará su poética de los heterónimos, expuesta en la reseña. A veces también los sueños son inventados a partir de obras presentadas en la segunda sección (es el caso para «la Vocazione di San Matteo» de Caravagio). Pero ocurre que la relación entre sueńo, obra y vida se deshace: ya sea que se ignora la proveniencia de un «biografema ${ }^{21}$ » («Pinky», la amiga de Debussy en su sueño, ¿está sacada de la obra o de la vida del músico? $\mathrm{O}$ aún ¿¿de la imaginación de Tabucchi, gracias eventualmente a un intertexto proustiano ${ }^{22}$ ?); ya sea que un elemento pueda interpretarse tanto en el plano referencial como en virtud de la lógica del sueño, como el personaje del pintor en el sueño de Cecco Angiolieri, posible imagen de un artista real o doble solar del sońador. El lector se encuentra entonces preso en la tela de un texto que, enigmático, se lee en relación a una serie de alusiones (a la vida, a la obra del artista) y se presenta a la vez como sueño, relato de sueño, relato de vida, pero también como interpretación de esta vida, aún como ensayo crítico.

Así, la escritura siempre singular a la que se abandonan nuestros biógrafos imaginarios confronta a sus lectores a una oscuridad voluntaria y los fuerza a arriesgarse a una aventura interpretativa mal asegurada.

En las obras que hemos examinado aquí, Schwob, Borges, Wilcock y Tabucchi participan innegablemente en la evolución que ha conocido la biografía ${ }^{23}$ desde hace más de un siglo y que se puede describir como un movimiento de subjetivación, de desacralización y de literarización. Practicando la forma breve, manejan de buen grado la alusión, la elipsis, el desenlace inesperado, pero también la recarga barroca o el detalle enigmático. Saben eventualmente mostrarse engañosos.

Sus afinidades y sus influencias cruzadas han sido frecuentemente relevadas por la crítica. Pierre Jourde comenta bromeando que Schwob «ha sido Borges antes que Borges (lo que es perfectamente borgiano) ${ }^{24}$ ", mientras que los redactores del sitio dedicado a Wilcock imaginan la presentación sintética que habría podido dar de él el autor de Vidas imaginarias: "Amava Wittgenstein, la poesia e la lettura del Scientific American» (così, forse, avrebbe potuto descriverlo Marcel Schwob)» ${ }^{25}$.

Hay sin embargo, que observar la singularidad de sus proyectos: si Schwob y Borges comparten la convicción de que la literatura es mundo y que el mundo es literatura, no es seguro que sean seguidos en este punto por Wilcock y por Tabucchi. Solicitando la función referencial en sus textos, el primero ordena al lector pronunciarse sobre la verosimilitud o no de los retratos que él junta y saca además de eso una parte de su fuerza provocadora. Tabucchi, por su parte, concibe su libro como un elemento que asegura un retorno a las obras del pasado y restablece sobre este punto el homenaje que constituía tradicionalmente la biografía. 


\section{Notas}

${ }^{1}$ Volveremos sobre la admiración que profesaban Marcel Schwob y Jorge Luis Borges hacia Thomas De Quincey. Marcel Schwob tradujo al francés Los últimos días de Emmanuel Kant en 1899.

${ }^{2}$ Señalemos a este respecto no solo el artículo de Bruno Fabre, «Des vies insolites: les Vies imaginaires de Marcel Schwob», Ecritures insolites, Recherches sur l'imaginaire (dir. Arlette Bouloumié, Cahier XXXIII, Angers, Presses de l'Université d'Angers, 2008, pp. 147-158), sino también la rúbrica en el sitio de la Sociedad Marcel Schwob que permite consultarlo, así como alrededor de sesenta artículos que tratan del mismo autor. http://www.marcel-schwob.org/?p=1824 (consultado en línea por la autora el 9 de septiembre de 2017).

${ }^{3}$ Foucault M. (1994). La vie des hommes infâmes. En Dits et écrits (Pp. 237-253). Paris: Gallimard, t. III. En estas páginas, Michel Foucault establece una correlación entre lo infame y lo ínfimo, en la medida en que la principal fuente dejada por los «ínfimos», los anónimos, está constituida por los archivos jurídicos y las minutas de procesos.

${ }^{4}$ En 1970, en su Ensayo de autobiografía, la confesión se mezcla con la denegación: «En Historia universal de la infamia no quería repetir lo que hizo Marcel Schwob en sus Vidas imaginarias». (Envío al artículo de Víctor Gustavo Zonana para un análisis crítico de la cita en su conjunto, p. 680.) En 1986, Borges reafirma su deuda en prefacio a la edición española de Vies imaginaires (Ver Obras completas, Barcelona, Emecé Editores, 1996, tomo IV, p. 486).

${ }^{5}$ Ver la nota 16 del artículo de Víctor Gustavo Zonana (De Virispessimis..., artículo citado, p. 677).

${ }^{6}$ En el número 2 de Spicilège. Cahiers Marcel Schwob, en 2009, Bruno Fabre propone un dossier sobre las traducciones de Vidas imaginarias. Las traducciones al español y al italiano están recopiladas en las páginas 116-118. ${ }^{7}$ Reseña publicada el 14 de enero de 1973 en el semanario Il Tempo, retomada en Descrizioni di descrizioni (Turín, Einaudi, 1979, pp. 29-33). ${ }^{8} \mathrm{La}$ cantidad casi equivalente de textos (veintidós y veinte); el recurso a aposiciones, en los subtítulos, para calificar a los personajes biografiados; la presencia de Villon y de Stevenson, dos autores caros a Schwob, y la de Cecco Angiolieri, ya personaje de Vidas imaginarias; la cobertura de la edición original en Sellerio, un detalle del Sueño de Pierre Puvis de Chavannes (1883), pintor simbolista francés.

${ }^{9}$ El Pais, $1^{\circ}$ de junio 1998, citado por P. Hualde Pascual («Vidas imaginarias de autores griegos...", artículo citado, p. 223).

${ }^{10}$ En el sentido en que lo entiende Gérard Genette.

${ }^{11} \mathrm{He}$ desarrollado este punto en "Deux épigones de Marcel Schwob dans la littérature italienne: J. Rodolfo Wilcock et Antonio Tabucchi», in Retours à Marcel Schwob. D'un siècle à l'autre (1905-2005), Presses Universitaires de Rennes, 2007, pp. 279-290. (Consultable on line en la dirección indicada en la nota 2.)

${ }^{12}$ «Sotto il mandorlo della tua donna, quando la prima luna d'agosto sorge dietro la casa, potrai sognare, se gli dèi sorridono, i sogni di un 
altro" (Tabucchi, 2001: 11). El autor, a quien le gusta llamarse selenófilo, se desdobla en un apóstrofe que hace de nuevo la parte de otro femenino, la compañera después de su hija.

${ }^{13}$ "conoscere i sogni degli artista che ho amato. Purtroppo quelli [...] non ci hanno lasciato i percorsi notturni del loro spirito» (Ibíd., p. 13). ${ }^{14}$ La nota (auto-) biográfica imaginada por Jorge Luis Borges para la edición de la Enciclopedia Sudamericana (Santiago, Chile) habla explícitamente de «declinación del país» (Obras completas, Emecé Editores, Buenos Aires, 1974, p. 1144). Por otra parte, la crítica ha frecuentemente relacionado el título de la colección de relatos con la designación corriente de los años 30 en Argentina (la «década infame»).

${ }^{15} \mathrm{He}$ desarrollado esta perspectiva crítica en "Rêves de rêves: un dialogue à trois voix», Otrante, n' 16,2004 , p. 141-153.

${ }^{16}$ Ver por ejemplo Bencheikh, Jamel-Eddine, «A propos des sources arabes d'un texte de J.L. Borgès: Le Teinturier Masqué: Hakim de Merv», Cahiers algériens de littérature comparée, 1966, nº 1, p. 3-10. El crítico establece que la lista de obras pretendidamente consultadas no es fiable (heterogeneidad, aproximaciones, olvidos, hasta invenciones como para el Manual del gigante o Libro de la precisión y la revisión) y que de todas formas, Borges no se siente obligado a respetarlas. $Y$ concluye «[Borges] no utiliza la "verdad " de las cosas más que para liberarse mejor de ellas cuando todo viene a confundirse bajo su pluma, el sueño y la historia, lo imaginario y lo real».

${ }^{17}$ Wilcock J.R., La Sinagoga degli iconoclasti, op. cit., p. 216. La obra de Martin Gardner, In the Name of Science (Dover, 1952), reeditada en 1957 bajo el título de Fads and Fallacies in the Name of Science (Dover), parte en campańa contra las teorías científicas que han tenido una cierta audiencia, pero juzgadas descabelladas, erróneas o peligrosas por el autor. El fin es claramente racionalista. Al relevamiento establecido por Wilcock, habría que agregar Socrates Scholfield, él también tomado de Martin Gardner.

${ }^{18}$ Pasolini, P.P., Descrizioni di descrizioni, op.cit., p. 28 : «Ridendo [...] come un pazzerello». «Senso di nausea». "Voglia di dimenticare».

${ }^{19}$ Estos dos personajes son tomados del libro de Martin Gardner.

${ }^{20}$ Ibíd., p. 78. Se podrá completar mi idea por lo que dice Bruno Fabre al final del artículo indicado en la nota 15.

${ }^{21}$ En el sentido en que lo entiende Roland Barthes en Sade, Fourier, Loyola (1971).

${ }^{22} \mathrm{Si}$ de «Pinky» se pasa a «dama en rosa» y entonces a Odette de Crécy, heroína de Un amor de Swann.

${ }^{23}$ Sobre esta cuestión, leer a Daniel Madelénat, La biograhie, Paris, PUF, 1984.

${ }^{24} \mathrm{http}: / /$ pierre-jourde.blogs.nouvelobs.com/marcel-schwob/ Consultado el 26 de septiembre de 2017.

${ }^{25} \mathrm{http}: / /$ www.wilcock.it/index.php?option=com_content\&view=article \&id=48\&Itemid=54 Consultado el 25 de septiembre de 2017 


\section{Referencias bibliográficas}

Bernès, J.P. (1993). Notice. En L'Histoire universelle de l'infamie, en Euvres de Jorge Luis Borges (pp. 1484). Colección Bibliothèque de la Pléiade, tomo I. Paris: Gallimard.

Borges, J.L. (1974). Historia universal de la infamia. En Obras completas. Buenos Aires: Emecé Editores.

DeLAY, F. (2006). Une énorme influence. Europe (925). 7-18.

Eissen, A. (2007). Deux épigones de Marcel Schwob dans la littérature italienne: J. Rodolfo Wilcock et Antonio Tabucchi. En Retours à Marcel Schwob. D'un siècle à l'autre (1905-2005) (pp. 279-290). Presses Universitaires de Rennes. Consulta on line: http://www.marcel-schwob.org/?p=1824. (2004). Rêves de rêves: un dialogue à trois voix. Otrante (16). $141-153$.

(2007). Le récit de rêve comme récit de vie. En Monluçon, A. y SalHa, A. Fictions biographiques XIX'e-XXIe siècles (Pp. 223-233) Toulouse: Presses Universitaires du Mirail («Cribles»).

Garcia Jurado, F. (2004). Borges como lector e intermediario entre M. Schwob y A. Tabucchi: el caso de las vidas imaginarias y la historiografía literaria latina. Variaciones Borges (18). 115-135.

JOURDE, P. (2009). http://pierre-jourde.blogs.nouvelobs.com/marcelschwob/

Louis, A. (1997). Jorge Luis Borges: œeuvre et manowures. Paris: L'Harmattan. PAscual, P. (1996). Vidas imaginarias de autores griegos en la literatura moderna (Schwob, Borges, Tabucchi). En Actas XII Simposio de la Sociedad Española de Literatura general y comparada (El retrato literario) (Pp. 217-225). Organizado por Universidad de Huelva.

Pasolini, P. P. (1979). Descrizioni di descrizioni. Torino: Einaudi.

Sсншов, M. (2004) Vies imaginaires. Presentación por Jean-Pierre Bertrand y Gérald Purnelle. Paris: Garnier-Flammarion (colección «GF»). _ (1972) Vite immaginarie. (Traducción: Fleur Jaeggy). Milano: Adelphi.

(2014). Vies imaginaires. De Plutarque à Michon (Selección y presentación de textos: Alexandre Gefen). Paris: Folio classique.

Tabucchi, A. (1992). Sogni di sogni. Palermo: Sellerio. 2001.

WiLcock, J.R. (1972). La sinagoga degli iconoclasti, Milan: Adelphi. 1990. Ziegler, R. (2009). L'art de l'amour et de la discorde dans Vies imaginaires de Marcel Schwob. Spicilège. Cahiers Marcel Schwob (2). 29.

Zonana, V. (2000). De viris pessimis: biografias imaginarias de Marcel Schwob, Jorge Luis Borges y Juan Rodolfo Wilcock. Revista de Filologia Hispanica, 16(3). 673-690. Recuperado de: http://dadun.unav.edu/ handle/10171/5370.

\section{Eissen, Ariane}

«La ficción biográfica entre Francia, Argentina e Italia (Schwob, Borges, Wilcock, Tabucchi)». El hilo de la fábula. Revista anual del Centro de Estudios Comparados (18), 91-102. 